\title{
Prevalence of helminthic infections and determinant factors among pregnant women in Mecha district, Northwest Ethiopia: a cross sectional study
}

\author{
Berhanu Elfu Feleke ${ }^{1 *}$ (D) and Tadesse Hailu Jember ${ }^{2}$
}

\begin{abstract}
Background: Intestinal parasites are the most common infections in developing countries. Prevalence and impacts of these parasites are high in pregnant women. The aims of this study were to determine prevalence of helminthic infection and evaluate the determinant factors during pregnancy.

Methods: A cross-sectional study was conducted in Mecha district from November 2015 to January 2016. The data were collected by interview technique and collecting the stool sample from each pregnant woman. Descriptive statistics and binary logistic regression were used.

Results: A total of 783 pregnant women were included. The prevalence of intestinal parasite among pregnant women was 70.6\% [95\% Cl $67-74 \%]$. Ascaris lumbricoides (32.7\%) was the predominant intestinal parasite species. Intestinal parasitic infection were 2.94 folds higher in the absence of latrine (AOR: 2.94 [95\% Cl: 1.5-5.8]). Absence of regular hand washing habit increase the odds of infection by 3.33 folds higher (AOR: 3.33 [95\% Cl: 1.54-7.14]). Not wearing shoe increased the odds of helminthic infection by 6.87 folds higher (AOR: 6.87 [95\% Cl: 3.67-12.9]). Illiteracy increases the odds of intestinal parasitic infection by 2.32 folds higher (AOR: 2.32 [95\% Cl: 1.04-5.26]). Ingestion of raw vegetables increases the odds of intestinal parasitic infection by 2.65 folds higher (AOR: 2.65 [95\% Cl: 3.23-9.9]). The odds of intestinal parasitic infection were higher in rural areas (AOR: 2 [95\% Cl: 5-10]). Intestinal parasitic infection was higher in women aged less than 21 years (AOR: 6.48 [95\% Cl: 2.91-14.4]).

Conclusion: The prevalence of helminthic infection is high in this study. Latrine utilization, hand washing habit, eating raw vegetables and bare foot were the major determinant factors for the high prevalence. Therefore, health education and improvements in sanitary infrastructure could achieve long-term and sustainable reductions in helminth prevalence.
\end{abstract}

Keywords: Prevalence, Determinants, Intestinal parasite, Pregnant women, Ethiopia

\section{Background}

Intestinal parasites especially geohelmenths are the most common and widespread of human parasites in the developing world [1]. Thousands of rural and impoverished villagers are often chronically infected with different species of parasitic worms [2]. More than 1.5 billion people, or $24 \%$ of the world's population, are infected with soil-transmitted

\footnotetext{
*Correspondence: elfufeleke@gmail.com; belfu@yahoo.com

${ }^{1}$ Department of Epidemiology and Biostatistics, University of Bahir Dar, Bahir Dar, Ethiopia

Full list of author information is available at the end of the article
}

helminthic infections worldwide. Infections are widely distributed in tropical and subtropical areas, with the greatest numbers occurring in sub-Saharan Africa, the Americas, China and East Asia [3].

Intestinal parasitic infection is very common in Ethiopia [4] and the magnitude of infection varies from place to place [5]. Intestinal parasitic infections account the second most predominant causes of outpatient morbidity in the country [6]. High prevalence of parasitic infection in Ethiopia were due to the unsafe and inadequate provision of water, unhygienic living conditions, the absence of

(C) The Author(s). 2018 Open Access This article is distributed under the terms of the Creative Commons Attribution 4.0 International License (http://creativecommons.org/licenses/by/4.0/), which permits unrestricted use, distribution, and 
proper utilization of latrine and habit of walking with a bare foot $[7,8]$.

Pregnant women are also at high risk of parasitic infection due to their close relationship with children [9]. Recently, a study done on pregnant women indicated that pregnancy has been associated with an increasing prevalence of parasitic infections compared to non-pregnant women [10].

Infections with helminth were associated with a modest decrease in hemoglobin levels and indicators of poor nutritional status. Helminthic infections, such as Hookworm, Trichuriasis, and Schistosomiasis, have been shown to directly contribute to severe anemia in patients through blood loss and micronutrient deficiencies [11]. Low hemoglobin level is associated within areas where with a high prevalence of Hookworm infection [12]. Hookworm is the leading cause of pathologic blood loss in endemic areas [13].

Anemia accounts $20 \%$ of maternal death globally [14]. Anemia in these highly endemic regions is common among pregnant women and often multi-factorial. Anemia has a devastating effect on pregnant women and has been associated with stillbirth, prematurity and low birth weight [15].

Although there are a lot of factors that causes anemia, intestinal parasites like Hookworm, Trichuriasis trichuira and schistosoma are highly associated to cause anemia in pregnant women in endemic parts of Ethiopia. These parasites cause anemia directly by feeding the red blood cells or indirectly by causing bleeding, feeding the micronutrients and infiltrating the blood forming organs. The complication of intestinal parasitic infection during pregnancy leads to stillbirth, prematurity and low birth weight. To minimize the burden of parasitic infection during pregnancy, studying the prevalence of intestinal parasitic infections in pregnant women is very ideal. Therefore, the aims of this study were to determine the prevalence and determinants of intestinal helminth among pregnant women in Northwest Ethiopia.

\section{Methods and materials}

A cross sectional study was conducted in Mecha district. Mecha district was located $40 \mathrm{~km}$ to the north of Bahir dar city and the district contains 376,000 residents. The data were collected from November 2015 to January 2016. The target population was all pregnant women residing in Mecha district. Pregnant women absent during the data collection period or unable to give stool sample were excluded from the study.

The sample size was calculated using single population proportion formula with the assumption of $95 \% \mathrm{CI}, 50 \%$ proportion of intestinal parasite in pregnant women, $5 \%$ margin of error, none response rate of $10 \%$ and a design effect of 2 gives 846 pregnant women's. Multistage sampling technique was used. First 10 kebeles (the smallest administrative unit in Ethiopia) were selected from 40 kebeles of Mecha district using simple random sampling technique. Then simple random sampling technique was used to select pregnant women from these 10 kebeles using the kebele health extension workers registration list as a sampling frame.

The data collection procedure was conducted using interview technique and collecting stool sample from each interviewed pregnant women. Fifteen health extension workers were recruited for the data collection and 5 clinical nurses were recruited for supervision. The stool sample was collected from each pregnant woman, preserved with $10 \mathrm{ml}$ sodium acetate- acetic acid-formalin solution (SAF) and transported to Bahir dar regional laboratory for analysis. From each pregnant woman, one gram stool sample was collected. Concentration technique was used. The stool sample was well mixed and filtered using a funnel with gauze then centrifuged for one minute at 2000 RPM (revolution per minute) and the supernatant was discarded. 7 ML (Milliliter) normal saline was added, mixed with a wooden stick, 3 ML ether was added and mixed well then centrifuged for 5 min at 2000 RPM. Finally, the supernatant was discarded and the whole sediment was examined for parasites [16].

To ensure the quality of this research, training was given for all data collectors and supervisors. The pre-test was conducted in 50 pregnant women then the necessary correction was done on the questionnaire after the pre-test. The whole data collection procedures were closely supervised by field supervisors and investigators.

We say the women practice proper hand hygiene if she washed her hands after visiting the toilet, before cooking food and before feeding her child. We say the women properly utilize toilets if the household members consistently utilize the toilets.

The data were entered into the computer using Epi-info software and transported to SPSS software for analysis. Descriptive statistics were used to estimate the prevalence of intestinal parasite and binary logistic regression was used to identify the determinants of intestinal parasite and variable with a $p$-value less than 0.05 was declared as determinants of intestinal parasite. Adjustments were done for age, gravidity, parity, ANC visit, religion, ethnicity, residence, ingestion of raw vegetables, latrine utilization, hand washing practice, bare foot and educational status.

\section{Results}

A total of 783 pregnant women were included giving a response rate of $92.55 \%$. The mean age of the responders was 20.3 years (Standard deviation [SD] 2.95 years). The majority (91.8\%) of respondents were orthodox Christian by religion. Amhara ethnicity constituted $87.9 \%$ of the study participants (Table 1). 
Table 1 Socio-demographic profile of pregnant women in Mecha district, Northwest Ethiopia $(n=783)$

\begin{tabular}{|c|c|c|c|c|}
\hline $\mathrm{SN}^{\mathrm{a}}$ & Population profile & & $\mathrm{N}^{\mathrm{b}}$ & Percentage \\
\hline \multirow[t]{3}{*}{1.} & Age & $16-20$ & 489 & 62.5 \\
\hline & & $21-25$ & 291 & 37.2 \\
\hline & & $>25$ & 3 & 0.4 \\
\hline \multirow[t]{2}{*}{2.} & Residence & Urban & 181 & 23.1 \\
\hline & & Rural & 602 & 76.9 \\
\hline \multirow[t]{2}{*}{3.} & Religion & Orthodox & 719 & 91.8 \\
\hline & & Muslim & 64 & 8.2 \\
\hline \multirow[t]{3}{*}{4.} & Ethnicity & Amhara & 688 & 87.9 \\
\hline & & Agaw & 74 & 9.5 \\
\hline & & Others & 21 & 2.6 \\
\hline \multirow[t]{7}{*}{5.} & Educational status & Illiterate & 194 & 24.5 \\
\hline & & Elementary & 458 & 58.5 \\
\hline & & Secondary & 36 & 4.6 \\
\hline & & Certificate & 43 & 5.5 \\
\hline & & Diploma & 16 & 2 \\
\hline & & First degree & 35 & 4.5 \\
\hline & & Second degree & 1 & 0.1 \\
\hline \multirow[t]{4}{*}{6.} & Gravidity & 1 & 263 & 33.6 \\
\hline & & 2 & 329 & 42 \\
\hline & & 3 & 185 & 23.6 \\
\hline & & 4 & 6 & 0.8 \\
\hline \multirow[t]{4}{*}{7.} & Frequency of ANC visit & 0 & 275 & 35.1 \\
\hline & & 1 & 314 & 40.1 \\
\hline & & 2 & 189 & 24.1 \\
\hline & & 3 & 5 & 0.6 \\
\hline \multirow[t]{3}{*}{8.} & Gestational age in weeks & $14-23$ & 157 & 20.1 \\
\hline & & $24-33$ & 293 & 37.4 \\
\hline & & $34-42$ & 333 & 42.5 \\
\hline
\end{tabular}

${ }^{\mathrm{a}} \mathrm{SN}$ serial number

${ }^{\mathrm{b}} \mathrm{N}$ number of women

The prevalence of intestinal parasite among pregnant women was 70.6\% [95\% CI $67-74 \%]$.

$60.8 \%$ of the infection was on high intensity of infection, $18.3 \%$ of the infection was on moderate intensity of infection and $21 \%$ of the infection was on low intensity of infection (Table 2).

The absence of latrine increases the odds of intestinal parasitic infection by 2.94 folds higher. The odds of intestinal parasitic infection were 3.33 folds higher among pregnant women that didn't have regular hand washing habit. Not wearing shoe increases the odds of intestinal parasitic infection by 6.87 times higher. Illiteracy increases the odds of intestinal parasitic infection by 2.32 folds higher. The odds of helminthic infections were 2.65 times higher in pregnant women that ingest raw vegetables.
Pregnant women whose age less than or equal to 21 years old were 6.48 times more likely to be infected with helminth than the others. The odds of intestinal parasitic infections were 2 folds higher in the rural areas (Table 3).

Table 2 The helminthic infection status of pregnant women

\begin{tabular}{lll}
\hline Parasites & $\begin{array}{l}\text { Number of } \\
\text { women infected }\end{array}$ & $\begin{array}{l}\text { Percentage of } \\
\text { women infected }\end{array}$ \\
\hline Ascaris lumbricoides & 256 & 32.7 \\
Schistosoma mansoni & 136 & 17.4 \\
Hookworm & 111 & 14.2 \\
Strongyloides stercolaris & 50 & 6.4 \\
Mixed infection & 42 & 5.36 \\
\hline
\end{tabular}


Table 3 Determinants of helminthic infection among pregnant women in Mecha district, Northwest Ethiopia $(n=783)$

\begin{tabular}{|c|c|c|c|c|c|c|}
\hline Variables & & aIP Infected & IP Not infected & ${ }^{b}$ COR[95\%Cl] & ${ }^{\mathrm{c} A O R}[95 \% \mathrm{Cl}]$ & $p$-value \\
\hline \multirow[t]{2}{*}{ Latrine } & Absent & 136 & 24 & $2.8[1.72-4.58]$ & $2.94[1.5-5.8]$ & $<0.01$ \\
\hline & Present & 417 & 206 & & & \\
\hline \multirow[t]{2}{*}{ Hand washing habit } & Absent & 182 & 15 & $7.03[3.94-12.74]$ & $3.33[1.54-7.14]$ & $<0.01$ \\
\hline & Present & 371 & 215 & & & \\
\hline \multirow[t]{2}{*}{ Residence } & Rural & 530 & 72 & $50.57[29.82-86.4]$ & $2[5-10]$ & 0.01 \\
\hline & Urban & 23 & 158 & & & \\
\hline \multirow[t]{2}{*}{ Bare footed } & Yes & 199 & 105 & $0.67[0.48-0.93]$ & $6.87[3.67-12.9]$ & $<0.01$ \\
\hline & No & 354 & 125 & & & \\
\hline \multirow[t]{2}{*}{ Educational status } & Illiterate & 135 & 59 & $0.94[0.65-1.35]$ & $2.32[1.04-5.26]$ & $<0.01$ \\
\hline & Literate & 418 & 171 & & & \\
\hline \multirow[t]{2}{*}{ Habit of eating raw vegetables } & Yes & 426 & 142 & $2.08[1.47-2.94]$ & $2.65[3.23-9.9]$ & $<0.01$ \\
\hline & No & 127 & 88 & & & \\
\hline \multirow[t]{2}{*}{ Age in years } & $<=21$ & 179 & 42 & 2.44 [1.44-3.19] & $6.48[2.91-14.4]$ & $<0.01$ \\
\hline & $>21$ & 374 & 188 & & & \\
\hline
\end{tabular}

IP=intestinal parasites

${ }^{\mathrm{b}}$ Crude odds ratio

${ }^{\mathrm{c} A d j u s t e d}$ odds ratio

\section{Discussion}

The prevalence of helminthic infection was $70.6 \%$ (95\% CI: $67-74 \%)$. This result was comparable with previous studies conduct in Uganda [17] and Venezuela [18], but higher than previous studies conducted in Ethiopia [19-21], and Kenya [22]. This might be due to difference in the socio-demographic factors and lack of awareness on prevention of parasitic infection.

The current high prevalence of Ascaris lumbricoides $(32.7 \%)$ is comparable with the previous study conducted in southern Ethiopia [20], Venezuela [18], and Kenya [22], but higher than studies done in western Ethiopia [21]. This difference may be due to the difference in altitude and awareness in the prevention of parasitic disease.

$14.2 \%$ of pregnant women were infected with hookworm. This result was higher than studies conducted in southern Ethiopia [23], and Niger Delta regions of Nigeria [24], but lower than previously reported data in western Ethiopia [21].

The prevalence of schistosoma among pregnant women was $17.4 \%$. This result was higher than studies conducted in Southeast Ethiopia [19, 23].

This study identified that intestinal helminth is underestimated public health problem among pregnant women and that socioeconomic factors play an important role in the establishment and spread of the infections in the communities.

Intestinal parasitic infection among pregnant women was determined by age, walking with bare foot, utilization of latrine, hand washing habit, and habit of eating raw vegetables.
Illiteracy increases the odds of intestinal parasitic infection in pregnant women by 2.32 folds higher. This result was in accordance with the previous study conducted in Kenya [25]. This might be due to the health-seeking behavior of literate pregnant women. The odds of intestinal parasitic infection were 2 folds higher in pregnant women living in the rural areas. This finding agrees with finding from south Ethiopia [23]. This is due to the reason that rural pregnant women have less access to the primary healthcare interventions. The odds of intestinal parasitic infections were 3.33 folds higher among pregnant women that didn't have regular hand washing habit. This finding was in line with previous study conducted in Nigeria [26]. This is due to the reason that proper hand washing practices breaks the chain of transmission for intestinal parasites. Not wearing shoe increases the odds of intestinal parasitic infection by 6.87 times higher. This finding was similar to the previous study conducted in Ethiopia [21]. This is due to the reason that soil-transmitted helminth like hookworm infection will be prevented from entering the susceptible host. Ingestion of raw vegetables increases the odds of intestinal parasitic infection by 2.32 folds higher. A similar previous finding was recorded in Southeast Ethiopia [19, 27]. This is due to the reason that raw vegetables acts as vehicle for transporting intestinal parasites [28-30].

\section{Conclusion}

A high prevalence of intestinal parasites was observed in pregnant women. Walking with bare foot, living in the rural area, illiteracy, age less than 21 years, the absence 
of proper utilization of latrine, poor hand washing practice and eating raw vegetables were associated factors with a high prevalence of intestinal parasitic infection during pregnancy. Therefore, health educations on hand wash and shoe wearing practice and improvements in sanitary infrastructure could achieve long-term and sustainable reductions in helminth prevalence among pregnant women.

\section{Abbreviation}

A.lumbricoides: Ascaris lumbricoides; AOR: Adjusted odds ratio; Cl: Confidence interval; COR: Crude odds ratio; ML: Milliliters; P-VALUE: Probability value; RPM: Revolution per minute; SAF: Sodium acetate- acetic acid-formalin solution; SD: Standard deviation

\section{Acknowledgments}

We would like to acknowledge federal democratic republic of Ethiopia for financially sponsoring this research work. The funder has no role in data collection, analysis of data and interpretation of data, writing of the manuscript and decision to send the manuscript for publication. We would also like to acknowledge Mecha Woreda health office for their unreserved cooperation during data collection stage. At last but not least we would also like to acknowledge all organizations and individuals that contributed to this work

\section{Author contribution}

BEF conceived the experiment; BEF and THJ performed the experiment, BEF plan the data collection process, BEF, and $\mathrm{THJ}$ analyzed and interpreted the data. BEF and $\mathrm{THJ}$ wrote the manuscript and approved the final draft for publication.

\section{Funding}

This research work was financially supported by the federal democratic republic of Ethiopia ministry of health. The funder has no role in the design of the study and collection, analysis, and interpretation of data and in writing the manuscript.

\section{Availability of data and materials}

The datasets used and/or analysed during the current study are available from the corresponding author on reasonable request.

\section{Competing interest}

The authors declare that they have no competing interests.

\section{Ethics approval and consent to participate}

Ethical clearance was obtained from Amhara national regional state health bureau with protocol number of 314/10-2015. Permission was obtained from Mecha Woreda health office. Written informed consent was obtained from each study participants. The name was not written on the questionnaire and the confidentiality of the data was kept properly. Pregnant women with intestinal parasitic infection were referred to the nearby health center for further investigation.

\section{Consent for publication}

Not applicable.

\section{Publisher's Note}

Springer Nature remains neutral with regard to jurisdictional claims in published maps and institutional affiliations.

\section{Author details}

'Department of Epidemiology and Biostatistics, University of Bahir Dar, Bahir Dar, Ethiopia. ${ }^{2}$ College of Medicine and Health Sciences, Bahir Dar University, Bahir Dar, Ethiopia.
Received: 12 December 2017 Accepted: 1 August 2018

Published online: 06 August 2018

\section{References}

1. Hotez PJ, Brindley PJ, Bethony JM, King CH, Pearce EJ, Jacobson J. Helminth infections: the great neglected tropical diseases. J Clin Invest. 2008:118(4):1311-21.

2. Hotez J, Molyneux H, Fenwick A. Control of neglected tropical diseases. N Engl J Med. 2007;357(10):1018-27.

3. WHO: Soil-transmitted helminth infections. Fact sheet In. Geneva: World health organization; 2015.

4. Tada I, Otomo H, Kaneko K, Yamaguchi T. Detecting techniques of parasite eggs in feces (in Japanese, Author's translation). Ishiyaku Pub. Inc: Tokyo; 1987.

5. Mengistu A, Gebre-Selassie S, Kassa T. Prevalence of intestinal parasitic infections among urban dwellers in Southwest Ethiopia. Ethiop J Health Dev. 2007;21(1):12-7.

6. Samuel F. Status of soil-transmitted helminthes infection in Ethiopia. American Journal of Health Research. 2015·3(3):170-6.

7. Habtamu B, Kloos H. The epidemiology and ecology of health and diseases in Ethiopia Addis Ababa. Ethiopia: Shama Books; 2006

8. Alemu M, Hailu A, Bugssa G. Prevalence of intestinal schistosomiasis and soil-transmitted helminthiasis among primary schoolchildren in Umolante district. South Ethiopia Clin Med Res. 2014;3(6):174-80.

9. Van Eijk AM, Lindblade KA, Odhiambo F, Peterson E, Rosen DH, Karanja D, Ayisi JG, Shi YP, Adazu K, Slutsker L. Geohelminth infections among pregnant women in rural western Kenya; a cross-sectional study. PLoS Negl Trop Dis. 2009;3(1):e370

10. Hotez PJ, Molyneux DH, Fenwick A, Kumaresan J, Sachs SE, Sachs JD, Savioli L. Control of neglected tropical diseases. N Engl J Med. 2007;357(10):1018-27.

11. Steketee RW. Pregnancy, nutrition and parasitic diseases. J Nutr. 2003;133(5): 1661S-7S.

12. Luoba Al, Wenzel Geissler P, Estambale B, Ouma JH, Alusala D, Ayah R, Mwaniki D, Magnussen $\mathrm{P}$, Friis $\mathrm{H}$. Earth-eating and reinfection with intestinal helminths among pregnant and lactating women in western Kenya. Tropical Med Int Health. 2005:10(3):220-7.

13. Brooker S, Bethony J, Hotez PJ. Human hookworm infection in the $21 \mathrm{st}$ century. Adv Parasitol. 2004:58:197-288.

14. Driskell JA. Nutritional AnemiaThe guidebook: nutritional Anemia. JAMA 2008:299(22):2690-1.

15. Elliott AM, Ndibazza J, Mpairwe H, Muhangi L, Webb EL, Kizito D, Mawa P, Tweyongyere $\mathrm{R}$, Muwanga $\mathrm{M}$. Treatment with anthelminthics during pregnancy: what gains and what risks for the mother and child? Parasitology. 2011;138(12):1499-507.

16. Institute S: Methods in Parasitology. In: Sodium acetate-acetic acid-formalin solution method for stool specimen. Basel: Swiss TPH: Swiss Tropical Institute; 2005. p. 1-18

17. Ndibazza J, Muhangi L, Akishule D, Kiggundu M, Ameke C, Oweka J, Kizindo $\mathrm{R}$, Duong $\mathrm{T}$, Kleinschmidt I, Muwanga M. Effects of deworming during pregnancy on maternal and perinatal outcomes in Entebbe, Uganda: a randomized controlled trial. Clin Infect Dis. 2010:50(4):531-40.

18. Rodríguez-Morales AJ, Barbella RA, Case C, Arria M, Ravelo M, Perez H, Urdaneta O, Gervasio G, Rubio N, Maldonado A: Intestinal parasitic infections among pregnant women in Venezuela Infect. Dis. Obstet. Gynecol. 2006, 2006

19. Kefiyalew F, Zemene E, Asres Y, Gedefaw L. Anemia among pregnant women in Southeast Ethiopia: prevalence, severity and associated risk factors. BMC Research Notes. 2014;7(1):1.

20. Tesfaye DJ, Beshir WG, Dejene T, Tewelde T: Prevalence of intestina helminthiases and associated factors among pregnant women attending antenatal Clinic of Nigist Eleni Mohammed Memorial Hospital, Hossana, Southern Ethiopia Open Access Library Journal 2015, 2.

21. Getachew M, Tafess K, Zeynudin A, Yewhalaw D: Prevalence soil transmitted helminthiasis and malaria co-infection among pregnant women and risk factors in Gilgel gibe dam area, Southwest Ethiopia BMC. Res. Notes 2013, 6(1):1.

22. Wekesa A, Mulambalah C, Muleke C, Odhiambo R: Intestinal helminth infections in pregnant women attending antenatal clinic at Kitale District hospital, Kenya J. Parasitol. Res. 2014, 2014.

23. Gedefaw L, Ayele A, Asres Y, Mossie A. Anaemia and associated factors among pregnant women attending antenatal care clinic in Walayita Sodo town, southern Ethiopia. Ethiopian journal of health sciences. 2015;25(2):155-64. 
24. Green Kl, Ojule JD. Helminthiasis in pregnancy in the Niger-Delta region of Nigeria. The Nigerian Health Journal. 2016;15(2):69.

25. McClure EM, Meshnick SR, Mungai P, Malhotra I, King CL, Goldenberg RL, Hudgens MG, Siega-Riz AM, Dent AE. The association of parasitic infections in pregnancy and maternal and fetal anemia: a cohort study in coastal Kenya. PLoS Negl Trop Dis. 2014;8(2):e2724.

26. Amuta E, Houmsou R, Mker S. Knowledge and risk factors of intestinal parasitic infections among women in Makurdi, Benue state. Asian Pac J Trop Med. 2010;3(12):993-6.

27. Mahande AM, Mahande MJ. Prevalence of parasitic infections and associations with pregnancy complications and outcomes in northern Tanzania: a registry-based cross-sectional study. BMC Infect Dis. 2016;16(1):1.

28. Omowaye O, Audu P. Parasites contamination and distribution on fruits and vegetables in Kogi,Nigeria. Cibtech Journal of Bio-Protocols. 2012;1(1):44-7.

29. Al-Binali AM, Bello CS, El-Shewy K, Abdulla SE. The prevalence of parasites in commonly used leafy vegetables in south western Saudi Arabia. Saudi Medical Journal. 2006;27(5):613-6.

30. Slifko TR, Smith HV, Rose JB. Emerging parasite zoonoses associated with water and food. Int J Parasitol. 2000;30(12-13):1379-93.

Ready to submit your research? Choose BMC and benefit from:

- fast, convenient online submission

- thorough peer review by experienced researchers in your field

- rapid publication on acceptance

- support for research data, including large and complex data types

- gold Open Access which fosters wider collaboration and increased citations

- maximum visibility for your research: over $100 \mathrm{M}$ website views per year

At BMC, research is always in progress.

Learn more biomedcentral.com/submissions 